\title{
Want to Interview a Politician? Ways to Prepare for Digital Vetting by Political Staffers
}

Anna Lennox Esselment, University of Waterloo

Alex Marland, Memorial University of Newfoundland

ABSTRACT This article outlines how the advent of digital-communications technology, particularly social media, has contributed to an increased wariness by political elites to grant interviews to researchers. Errant remarks, misquotes, and comments taken out of context can exact a heavy price. Thus, politicians and their gatekeepers are far more cautious and risk averse than in decades past, which puts qualitative research methods-and the rich data they produce-in peril. Insights drawn from 32 qualitative, semi-structured interviews with social scientists, political journalists, and political staffers in six countries revealed that academics who submit interview requests should expect to be subjected to online scrutiny - a vetting-by gatekeepers before any access is granted. Digital screening aims to assess the authenticity and objectivity of the researcher. Our findings suggest that scholars who want to pursue qualitative research with politicians must practice online reputation management and perhaps even delve into personal marketing.

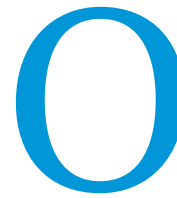

btaining interviews with politicians is difficult. We are among what appears to be a declining number of political scientists who have conducted hundreds of in-depth interviews with current and former heads of government, cabinet members, members of legislative assemblies, political consultants, election candidates, public servants, and others. We have learned that submitting interview requests must evolve with changing political and technological environments. Researchers today must adapt to the fast-paced political atmosphere of triage and suspicion. Social media firestorms, instantaneous news, opponents trolling for controversy, comments going viral-all of this puts political offices on edge. Gatekeepers have increasing reason to block an academic's request from ever making it to the intended participant. This research barrier is a serious problem for political science. A precipitous decline in qualitative data collection means that we are in peril of losing the context, nuances, and rationales for behavior that can be provided only by those immersed in political and public decision making (Curry 2017; McDonald and Mooney 2011). It also means

Anna Lennox Esselment ${ }^{(D)}$ is associate professor of political science at the University of Waterloo. She can be reached at alesselm@uwaterloo.ca.

Alex Marland is professor of political science at Memorial University of Newfoundland. He can be reached at amarland@mun.ca. that refining techniques to secure interviews is crucial; in the face of nonresponse, researchers should be wary about relying on referrals (i.e., "snowball" sampling), which can generate nonrepresentative data.

We want to improve the ability of social scientists to obtain interviews with politicians. Sharing our personal experiences is of limited value because they are particular to our individual practices in a single country. Therefore, we recently conducted 32 qualitative, semi-structured interviews with social scientists, political journalists, and political staffers in Australia, Canada, New Zealand, South Africa, the United Kingdom, and the United States to find out what they recommend. We asked: What are some of the most effective ways to establish contact with a politician? What happens when a political office receives a request for an interview? What advice can you offer about working with gatekeepers to secure an interview? How do digital communication and social media have implications for researchers' ability to connect with public officeholders? (For methodological details, see Marland and Esselment 2018.)

The digital environment is a disruptor to traditional qualitative research methods for reasons outlined herein. Qualitative researchers might overlook the importance of their virtual footprint in procuring an interview with a politician; however, we discovered that cybervetting is a natural response to requests for interviews, and the scrutiny puts the academic under a microscope. 
It turns out that a researcher is subject to online inspection from the moment the interview request is submitted. To augment the chances of being granted interviews with political elites, we believe that scholars must practice online reputation management and delve into personal marketing.
The professionalism or apparent objectivity of a researcher in their public writings can offset potential negatives that someone might see. What matters is a sense of trust that the professor will follow the facts. The impression that some politicians have of the objectivity or impartiality of a professor can impact their decision about whether to participate.

\section{Qualitative researchers might overlook the importance of their virtual footprint in procuring an interview with a politician; however, we discovered that cybervetting is a natural response to requests for interviews, and the scrutiny puts the academic under a microscope.}

\section{WHY DO GATEKEEPERS VET?}

Proactive vetting of a person's past and present is a routine component of public relations damage control. Cybervetting extracts available online information about anyone affiliated with the brand (Berkelaar and Harrison 2017). Scrutinizing Facebook, Instagram, LinkedIn, Twitter, and other online content is fair game for researchers planning an interview and for potential participants to do the same about researchers. Entering a name into Google, even for only a quick look, is so instinctive that it is a routine part of how researchers and political offices process an interview request.

Vetting is linked to caution among political elites and their staff toward anyone they do not know. The threat of political subterfuge is ever present: interviewers can be interns hired to dig up dirt on opponents (Tolley 2015, 216) or comedians trying to embarrass politicians who participate in bogus interviews (Lowry 2018). Compounding this is the partisan divide about higher education, with those on the political right taking aim at liberal hotbeds (Pew Research Center 2017), making it particularly difficult for academics to connect with conservatives. Even when a politician trusts an interviewer-perhaps because a reliable source vouched for that individual's reputation for discreetness-trouble may arise when information is shared online, the participant is misquoted, or remarks are taken out of context. The only guarantee that a politician has about granting an interview is a loss of precious time and risk exposure. The problem of accessibility is less acute among politicians who are rarely approached for an academic interview, who are particularly interested in the topic, and/or who support scholarly research.

The political staffers, journalists, and academics that we interviewed affirmed that public officeholders are always on guard. "Politicians are terrified of saying the wrong thing, of making a mistake...they are very risk averse. Politicians would rather say no and say nothing than say the wrong thing," an Australian political staffer explained. The wariness with which political elites approach the media extends to interactions with academics. Some politicians designate their staff to guard a firewall to protect them.

The common message relayed by our participants was that access to politicians is granted most often when staff are convinced of a researcher's professionalism and objectivity. An American journalist observed that a gatekeeper must believe that researchers are "on the level" about their intentions. Staff must be able to quickly form a positive assessment of researchers. A Canadian political staffer expressed it this way:
Gatekeepers told us that online vetting of academics is routine protocol. They peruse whatever an online search engine turns up, examine Facebook pages and Twitter feeds, and might even browse publicly available research papers. They want a sense of the researcher's reputation and whether the politician will be treated fairly. They want to know whether the academic has made public statements that suggest a lack of impartiality or discretion. It is "less a vetting of ideology than of authenticity," as an American political staffer put it.

\section{WHAT A RESEARCHER CAN DO: MARKET YOURSELF}

One British political staffer was succinct in her advice to academics seeking an interview: "You are marketing yourself." Researchers need to turn the tables on vetting and give themselves an advantage in the digital market. Personal marketing, or strategic self-promotion, requires attention from researchers hoping to land interviews with political elites. Peters' (1997) article "The Brand Called You" introduced the concept of personalized branding. He urged individuals to reflect on their personal and professional strengths, consolidate them into a personal brand, and use that as a platform to set and achieve professional goals. Whereas academics may not be entirely comfortable with the "Me Inc." world outlined by Peters, he does impart a useful lesson about impression management. The power to "curate [a] digital identity" (Marshall 2015) that is positive, engaging, and professional is increasingly crucial for qualitative researchers and is a version of Goffman's (1959) presentation of self in an online environment. Academics can read their profession's magazines for suggestions on how to become digitally savvy self-marketers (Connelly and Ghodsee 2011; Matthews 2016; Meyers 2012); however, efforts to self-brand can be challenging (Labrecque, Markos, and Milne 2011). Our interviews identified several ways that scholars can use online reputation management to increase their chances of gaining access to politicians.

Political staffers explained that online vetting is standard with a new contact. Researchers who go by different names should be conscious about whether a stranger can match them with the information provided to the political office. The starting point for a search is often an institutional webpage that follows an institutional format, such as listing research and teaching interests, recent publications, contact information, and a photograph. Researchers exercise more personal control over other online forums. LinkedIn is a popular option that is frequented by practitioners and easy to maintain. Advantages of building a personal website include using your name on a web domain, highlighting research interests, providing details about publications, listing awards, expanding on courses 
taught and teaching philosophy, listing working papers and grants, noting membership in professional associations, attaching links to social media accounts, and posting a full curriculum vitae.

Creating a profile on third-party research platforms is another way to assert some control over the vetting process. The academic social-networking sites Academia.edu and ResearchGate offer gatekeepers an assurance of authenticity. Scholars can upload their publications (subject to publisher copyright) that otherwise are inaccessible to practitioners because of paywalls. The sites track followers, citations, and mentions. Another option is a public profile on Google Scholar, which lists all publications associated with a researcher's career and provides citation counts. The analytic turn in assessing academic impact across the globe suggests that some gatekeepers will be sensitive to these metrics (Duffy and Pooley 2017, 3).

Most practitioners are unlikely to be interested in scholarly bona fides compared with a researcher's public profile and commentary in nonacademic forums. Political offices are interested in news stories about a researcher, participation in public panels, quotes in political news stories, op eds, and blogs. Microblogs, photo sharing, and other forms of social networking comprise the currency of political communication. A researcher who frequently comments on popular platforms such as Facebook, Instagram, and Twitter can be sure that their profile, photographs, and posts will be reviewed. A high number of followers may impress a gatekeeper of your importance, and like-minded convictions could reduce anxiety about the potential of a hidden agenda. Conversely, unprofessional profile photographs and off-putting biographies are red flags, and gatekeepers may avoid academics who offer public commentary. A researcher whose opinions differ sharply from the politician's signals that the interview is likely to be adversarial and should be avoided. More broadly, a researcher should be vigilant about deleting unseemly photographs and video, promoting only those that exude scholarly authenticity (Keiser 2018). A litmus test is to consider whether your public profile conveys professional neutrality. A single remark or image that increases your chances of participation in some ideological quarters may constitute grounds for immediate cutoff in others. results with gatekeepers. All researchers seeking to interview a politician should consider submitting a one-page researcher profile with the initial contact. Submitting a one-pager resolves a gatekeeper's need for information. It is an opportunity to develop a personal connection and break down academic barriers. It also can propel the vetting process to desirable digital spaces that showcase a researcher's bona fides in both scholarly and nonscholarly forums. Ideally, the profile will be viewed by gatekeepers before they undertake online intelligence gathering and before they consider background information about your research, potential discussion questions, a consent form, and anything else required by a research-ethics board. A concisely written profile should tell your story. This might include stating your research interests and your most important research accomplishments. Mention any awards or public recognition that will impress that you are a reputable scholar. Include hyperlinks to your social media accounts as an invitation to browse your statements and posts.

The one-page profile should avoid scholarly conventions that some practitioners will see as pompous, such as including an initial in your name. Instead, perhaps mention a hobby or favorite sports team to connect on a personal level. You might state where you went to school and your original community. A brief remark about family might be included. Ultimately, the profile must establish that you are trustworthy. The summary ideally will include testimonials from reputable public figures attesting to your commitment to being discreet and even-handed. When recruiting people who can vouch for you with a testimonial, consider the symbolism of gender balance, race, and the value of multi- or non-partisanship. More prolific scholars may want to include digital images of books they authored or edited. A carefully crafted one-page researcher profile can positively position that first interaction. In our experience, the profile is an excellent mechanism to turn the problem of vetting into an opportunity, irrespective of your cyber acumen.

WHAT A RESEARCHER CAN DO: VETTING THROUGH VOUCHING

Vetting by political staffers and politicians is reduced when someone the politician knows vouches for the researcher. Vouching for

\section{A litmus test is to consider whether your public profile conveys professional neutrality. A single remark or image that increases your chances of participation in some ideological quarters may constitute grounds for immediate cutoff in others.}

Researchers hoping to impress rather than repel a gatekeeper must monitor and police what appears online. Because posts on Twitter and similar applications can be wielded in a way to deliberately tarnish a researcher's reputation, the notification functions provided by these platforms can be helpful for tracking mentions on social media and identifying instances where deleting a tweet or blocking another user is recommended. Google Alerts works in a similar way: researchers receive emails alerting them to new web content that mentions their name, which assists with proactively managing their online reputation.

\section{WHAT A RESEARCHER CAN DO: DIRECT THE VETTING BY SUBMITTING A RESEARCHER PROFILE}

Experience has taught us that embracing the vetting process through strategic but direct self-promotion can have positive the validity and authenticity of others is standard procedure in qualitative research methods as well as in matters of exercising democratic rights (e.g., voting) (Schaffer and Wang 2009, 402-403). The political staffers we interviewed warned against deliberate attempts to bypass them, which undermines and devalues their role as gatekeepers. They welcome an acquaintance of the politician contacting them directly because this alleviates their responsibility to independently vet the researcher. Vouching establishes that the request needs to be presented to their boss.

Former politicians, political staffers, and even some political scientists have solidified friendships with numerous current officeholders who they can contact via personal email or telephone. In our experience, an intermediary can magically convert months of nonresponse with a political office into a gregarious willingness to participate (Marland 2019). The academics 
we interviewed relayed similar experiences, particularly when they did not have strong existing networks of their own, which requires additional ingenuity. They perform the classic snowballing practice of asking participants to put them in touch with other prospective interviewees. Other ways of locating a
Researchers must embrace and even invite cybervetting. Use digital tools to your advantage. Create and maintain academic websites that are transparent about your research projects, publications, teaching, and even public commentary. Use LinkedIn because political staffers do. Go beyond a university faculty

\section{The political staffers we interviewed warned against deliberate attempts to bypass them, which undermines and devalues their role as gatekeepers.}

go-between include approaching guest speakers in a course; reaching out to former students; and asking coworkers, friends, and family.

Although vouching can open doors and skirt the vetting process, researchers nevertheless should engage in personal marketing and online reputation management. Vouching enables valuable connections, but our academic respondents noted that those contacts often share certain characteristics-partisanship, age, gender, ideology, and region-that limit the usefulness of the data. Even with vouching, a researcher will be cybervetted. Scrutiny will increase when they seek out other interviewees who cannot be accessed through vouching. Curating a digital identity that showcases a scholar's objectivity and authenticity, combined with providing a one-page researcher profile with the initial contact, eases the vetting process for gatekeepers. Ultimately, these efforts should increase the potential that a request to interview a politician will be granted.

\section{WHAT ELSE CAN A RESEARCHER DO?}

Our research gleaned further advice for landing interviews with political elites. Some tips include availing of overlooked or underused methods, such as telephoning a political office in advance to alert them to a forthcoming email request; being mindful of the legislative calendar to maximize availability; and exploring a partnership with a nonpartisan organization to demonstrate third-party support for the research being conducted (Marland and Esselment 2018). However, of all the tips we compiled, being aware of the significance of your digital footprint carries the heaviest weight, and submitting a one-page profile before overwhelming gatekeepers with research-ethics documentation is the most important to convey.

\section{SUMMARY}

Gaining access to politicians is always challenging. Digital communication requires that researchers adjust traditional approaches to seeking an interview. Politicians are wary; their gatekeepers are cautious. The impact of low participation rates is disconcerting because social scientists become discouraged about requesting interviews and are drawn to free repositories of online data that can be mined and statistically analyzed. The conversations we had with political staffers, journalists, and academics revealed something valuable: a digital environment offers researchers more control over their own reputation, which can make the pathway to politicians less arduous. The value of personal marketing through online reputation management is a key facet of reinvigorating elite interviewing by researchers. profile and use popular academic sites such as ResearchGate and Academia.edu to post your publications. Link these digital platforms to one another to deepen your online presence and improve search-engine optimization. Manage your social media platforms so they conform to the professional and objective standards that gatekeepers seek. Whether you are a digital native or a luddite, prepare to influence the vetting process by providing gatekeepers with a one-page profile that gives them the information they need to know about you, including your accomplishments and testimonials. Provide the websites you want them to visit. As much as possible, direct the vetting process yourself and present a desired frame.

The gatekeepers we spoke with were clear that vetting is foremost about determining authenticity. Researchers must consistently uphold ethical and objective standards. Keep confidences, honor off-the-record remarks, guard anonymity, and maintain trust. Avoid the urge to post juicy interview insights that may result in short-term gain (e.g., interest from the press) but that jeopardizes securing future respondents for you and others. An authentic researcher is reliable, trustworthy, discreet, and impartial. Commitment to these standards should be clearly communicated in the digital spaces that a researcher uses for self-presentation and should be upheld through their actions.

Promote or perish.

\section{REFERENCES}

Berkelaar, Brenda L., and Millie A. Harrison. 2017. "Cybervetting." In The International Encyclopedia of Organizational Communication, eds. Craig R. Scott and Laurie Lewis, $1-7$. Hoboken, NJ: John Wiley \& Sons. Available at https://doi.org/ 10.1002/9781118955567.wbieoco54.

Connelly, Rachel, and Kristen Ghodsee. 2011. "The Value of Self-Promotion." Inside Higher Ed, July 18. Available at www.insidehighered.com/advice/2011/ 07/18/value-self-promotion.

Curry, James M. 2017. "In-Depth Qualitative Research and the Study of American Political Institutions.” PS: Political Science \& Politics 5o (1): 114-20.

Duffy, Brooke Erin, and Jefferson D. Pooley. 2017. “Facebook for Academics': The Convergence of Self-Branding and Social Media Logic on Academia.edu." Social Media + Society 1: 1-11.

Goffman, Erving. 1959. The Presentation of Self in Everyday Life. New York: Anchor Books.

Keiser, Amelia. 2018. "How to Remove a Picture or Image from Google." BrandYourself Available at https://brandyourself.com/blog/guide/how-to-remove-a-picture-orimage-from-google.

Labrecque, Lauren I., Ereni Markos, and George R. Milne. 2011. "Online Personal Branding: Processes, Challenges, and Implications.” Journal of Interactive Marketing 25: 37-50.

Lowry, Brian. 2018. "Sacha Baron Cohen Punks Politicians in 'Who Is America?" CNN, July 17. Available at www.cnn.com/2018/07/15/entertainment/who-isamerica-review/index.html

Marland, Alex. 2019. "Gaining Interview Access to Political Party Elites." SAGE Research Methods Cases. Available at https://dx.doi.org/10.4135/ 9781526477439 . 
Marland, Alex, and Anna Lennox Esselment. 2018. "Negotiating with Gatekeepers to Get Interviews with Politicians: Qualitative Research Recruitment in a Digital Media Environment." Qualitative Research. Available at doi:10.1177/1468794118803022.

Marshall, Kelli. 2015. "How to Curate your Digital Identity as an Academic." Chronicle of Higher Education. Available at www.chronicle.com/article/How-toCurate-Your-Digital/151001.

Matthews, David. 2016. "Secret Shoppers 'Pimp' Academics' Online Profiles." Times Higher Education. Available at www.timeshighereducation.com/news/ secret-shoppers-pimp-academics-online-profiles.

McDonald, Michael P., and Christopher Z. Mooney. 2011. "'Pracademics': Mixing an Academic Career with Practical Politics.” PS: Political Science E Politics 44 (2): 251-53.
Meyers, Katy. 2012. "Branding Yourself: Not as Painful as You Think." Inside Higher Ed. Available at www.insidehighered.com/blogs/gradhacker/branding-yourself-notpainful-you-think.

Peters, Tom. 1997. "The Brand Called You." Fast Company. Available at www. fastcompany.com/28905/brand-called-you.

Pew Research Center. 2017. "Sharp Partisan Divisions in Views of National Institutions." Available at www.people-press.org/2017/o7/10/sharp-partisandivisions-in-views-of-national-institutions.

Schaffer, Frederic C., and Tova A. Wang. 2009. "Is Everyone Else Doing It? Indiana's Voter Identification Law in International Perspective." Harvard Law Policy Review 3 (2): 397-412.

Tolley, Erin. 2015. Framed: Media and the Coverage of Race in Canadian Politics. Vancouver, BC: UBC Press. 